\title{
Effects of the male antifertility agent ornidazole on sperm function in vitro and in the female genital tract
}

\author{
C. H. Yeung ${ }^{1}$, G. Oberländer ${ }^{1,2}$ and T. G. Cooper ${ }^{1 *}$ \\ ${ }^{1}$ Institute of Reproductive Medicine of the University, and ${ }^{2}$ Institute of Special Zoology and \\ Comparative Embryology of the University, Steinfurter Straße 107, D-48149 Münster, Germany
}

\begin{abstract}
Infertility is induced in male rats by oral administration of $400 \mathrm{mg}$ ornidazole $\mathrm{kg}^{-\mathrm{I}}$ body mass day ${ }^{-1}$ within 10 days, without drastic effect on the motility of epididymal spermatozoa obtained after 15 days of treatment. Spermatozoa were recovered from the female tract $9 \mathrm{~h}$ after mating with males treated with ornidazole for 10 days to identify the cause of infertility. The number and motility of spermatozoa in the uterus indicated normal seminal deposition. Spermatozoa could pass the utero-tubal junction but total numbers of spermatozoa and their velocities in the oviductal isthmus were significantly lower than those recovered from females mated to fertile, control males fed vehicle alone. However, the number of spermatozoa recovered from the ampulla was not different from control and the number of spermatozoa that had penetrated the cumulus mass was lower and none of the eggs was fertilized by spermatozoa from rats treated with ornidazole. The ability of cauda epididymal spermatozoa from ornidazole-fed rats to penetrate viscous media in vitro was lower than that of the controls. When incubated in media containing different concentrations of substrates and ions, a reduction in movement of spermatozoa was observed when glucose was the only exogenous substrate or after preincubation in substrate-free medium. These results indicate that the antifertility action of orally administered ornidazole occurs via damage to spermatozoa in the upper regions of the female tract, possibly reflecting a failure in capacitation as a result of reduced energy production.
\end{abstract}

\section{Introduction}

The nitro-imidazole derivative ornidazole (2(chloromethyl)2methyl 5-nitroimidazole I-ethanol), used as an antimycotic drug in humans is an antifertility agent for rats (McClain and Downing, 1988a, b). It is active after oral gavage within 10 days and its action is fully reversible within 7 days of withdrawal of the drug (Oberländer et al., 1994) and this action is consistent with effects on the epididymis rather than the testis. This is in contrast to the action of other nitroimidazole derivatives that cause infertility after much longer periods by affecting spermatogenesis (Patanelli, 1975). The initial findings of subjective changes in the motility of caudal spermatozoa of affected animals (McClain and Downing, 1988a) has been substantiated by more thorough investigation and quantification using computer-assisted sperm analysis (CASA) techniques that show that only spermatozoa in the distal half of the epididymis are affected; the spermatozoa are motile but their velocities are reduced by 50\% (Oberländer et al., 1994). However, because the major epididymal secretions are not reduced in infertile animals, a direct action on spermatozoa in the cauda epididymidis is implicated (Oberländer et al., 1994). This action probably involves a metabolite rather than ornidazole itself, since incubation of spermatozoa in vitro with

${ }^{*}$ Reprint requests.

Received 17 August 1994. extremely high concentrations is required for any effect on kinematic parameters.

Although the output of spermatozoa of ornidazole-fed, infertile rats is normal, as judged from the testicular and epididymal masses, and they mate with receptive females, it is still possible that infertility stems from an effect on the mating behaviour resulting from abnormal ejaculation which leads to an inadequate number of spermatozoa being deposited in the uterus. Alternatively, ejaculated spermatozoa may not survive or negotiate obstacles in the female tract because of impaired energy metabolism, or a defect in sperm-egg interaction despite normal sperm transport. The aim of the present study was to elucidate the cause of infertility in male rats fed ornidazole, by recovering and examining spermatozoa from each compartment of the female tract after mating. In addition, the motility of cauda epididymal spermatozoa was examined in media containing different substrates and raised viscosity to detect any effects of altered energy metabolism.

\section{Materials and Methods}

Handling of males and mating schedule (Expt 1)

Adult male rats (Charles River Sprague-Dawley, 400-450 g body mass) of proven mating proficiency were fed ornidazole ( $400 \mathrm{mg} \mathrm{kg}^{-1}$ body mass day ${ }^{-1}$ ) by oral gavage for 10 days, 
or the same volume of vehicle (distilled water containing $0.2 \%$ $(w / v)$ carboxymethylcellulose and 2 drops Tween 20 per $100 \mathrm{ml} ; 0.14 \mathrm{ml}$ per $100 \mathrm{~g}$ body mass day ${ }^{-1}$ ), after they were mated with intact females for the assessment of pretreatment fertility, as described by Oberländer et al. (1994). On days 7 and 10, the fertility of rats was tested by pairing each with a pro-oestrous female, and mating was confirmed by the presence of spermatozoa in the vaginal smear on the following morning. Females from matings on day 7 were killed by $\mathrm{CO}_{2}$ asphyxiation 12 days later and the numbers of fetuses and corpora lutea were determined. For mating on day 10 , the female was introduced to the male at $00.30 \mathrm{~h}$ and removed at $01.30 \mathrm{~h}$ because under these conditions mating occurs within 20-30 min of pairing (Shalgi and Kraicer, 1978). On the day spermatozoa were obtained from the male, blood was taken from its tail vein for assessment of packed cell volume.

\section{Assessment of spermatozoa in the female tract after mating}

After successful mating, as determined by the presence of spermatozoa in vaginal smears, female rats were anaesthetized with urethane $\left(1.5 \mathrm{~g} \mathrm{~kg}^{-1}\right.$, i.p.) and the reproductive tracts exposed by a longitudinal abdominal incision. The base of the uterine cornua was clamped to prevent loss of spermatozoa during subsequent manipulation. The two uterine horns were removed after tying off the bases and were washed with PBS. The tied end was cut and the contents drained into a preweighed tube, and the uterus was rinsed with $0.2 \mathrm{ml}$ medium H (Yeung et al., 1992) injected just beneath the utero-tubal junction. An aliquot of the sperm suspension was diluted in medium $\mathrm{H}$ and a video-recording made for manual counting of percentage motility. Hyaluronidase ( $100 \mu \mathrm{l}, 5 \%(\mathrm{w} / \mathrm{v})$ in phosphate-buffered saline (Dulbecco's Life Technologies Ltd, Paisley)) was added to the rest of the sperm suspension for $30 \mathrm{~min}$ at room temperature to disperse any aggregations of spermatozoa (Turner and Cesarini, 1983). Triplicate aliquots of the sperm suspension were diluted with $2 \%(\mathrm{v} / \mathrm{v})$ formalin for assessement of number of spermatozoa.

The contents of the ampulla were released, by tearing the thin side of the capsule, into medium $\mathrm{H}(35 \mu \mathrm{l})$ containing $0.4 \%$ $(w / v)$ hyaluronidase on a siliconized slide. A coverslip was lowered onto the drop, supported by two layers of Parafilm ${ }^{\mathbb{R}}$ to make a deep chamber. The total amount was inspected for the presence of spermatozoa free in fluid surrounding the cumulus mass. The slide was then left in a humid box for $1 \mathrm{~h}$ to disperse the cumulus mass. The coverslip was then depressed to squash the eggs and reveal spermatozoa hidden in the cumulus mass and the number of spermatozoa was determined. The additional spermatozoa were taken to represent those in the cumuli. The number of total and fertilized eggs was also assessed; the presence of a sperm tail in the ooplasm was taken as an indicator of fertilization.

Spermatozoa from the oviductal isthmus were flushed with medium $\mathrm{H}$ by cannulating the ampullary junction and collecting the contents from the severed end at the uterotubular junction. The number of spermatozoa and the percentage motility were recorded, and a CASA assessment made according to the procedure of Yeung et al. (1992).

\section{Assessment of the migration of spermatozoa through viscous} medium

A male that had mated with the female on day 10 was fed ornidazole for an extra day. On the next day, the rat was anaesthetized with urethane ( $1.5 \mathrm{~g} \mathrm{~kg}^{-1}$, i.p.); a length of the cauda epididymal tubule just distal to the cauda flexure was dissected; and $0.5 \mathrm{~cm}$ segments (prepared by ligation of both ends with $8 / 0$ silk thread) were incubated in medium $\mathrm{H}$ at $34^{\circ} \mathrm{C}$ for up to $1 \mathrm{~h}$. Spermatozoa from the segment were released into medium $\mathrm{H}$ at a concentration of about $6 \times 10^{6} \mathrm{ml}^{-1}$. A flat capillary $5 \mathrm{~cm}$ long $(0.3 \mathrm{~mm}$ inner thickness. Camlab Ltd, Cambridge), filled with $1.5 \%(\mathrm{w} / \mathrm{v})$ methylcellulose in medium $\mathrm{H}$ (see below) and closed at one end with Critoseal ${ }^{(\mathbb{R})}$, was placed horizontally with its open end immersed in a $50 \mu \mathrm{l}$ aliquot of the sperm suspension in an Eppendorf tube. After incubation at $34^{\circ} \mathrm{C}$ for 1.5 and $4.5 \mathrm{~h}$, the capillary tube was removed from the suspension and the distances travelled by the first spermatozoon and the tenth spermatozoon were measured with a micrometer.

\section{Motility parameters of spermatozoa in different media}

Spermatozoa from the cauda epididymal segment were released into Sarstedt tubes containing $100 \mu \mathrm{l}$ medium $\mathrm{H}$ (containing $5 \mathrm{mmol}$ glucose $\mathrm{I}^{-1}, 12.5 \mathrm{mmol}$ lactate $\mathrm{I}^{-1}$, $0.25 \mathrm{mmol}$ pyruvate $\mathrm{l}^{-1}$ and $4 \mathrm{mg}$ albumin $\mathrm{ml}^{-1}$ ), medium $\mathrm{H}^{\prime}$ lacking glucose, medium $\mathrm{H}$ lacking lactate and pyruvate, medium $\mathrm{H}$ lacking all substrates and albumin and medium $\mathrm{H}$ containing high $\mathrm{K}^{+}\left(25 \mathrm{mmol} \mathrm{l^{-1 }}\right.$ substituting for an equivalent amount of $\mathrm{Na}^{+}$). After incubation at $34^{\circ} \mathrm{C}$ for 0,3 and $7 \mathrm{~h}$, aliquots were diluted to about 1:5 with the same medium (except for the medium lacking substrates, in which sperm suspensions were diluted with medium $\mathrm{H}$ to induce motility) to a concentration of about $0.3 \times 10^{6} \mathrm{ml}^{-1}$, placed in a $40 \mu \mathrm{m}$ deep siliconized slide chamber and a videotape was made for later analysis of motility parameters using the HamiltonThorne computerized system for 20 frames at 7 frames $\mathrm{s}^{-1}$ (Yeung et al., 1992). For each parameter, the median value from about 100 sperm tracks was taken for each sperm sample.

\section{Fertility of ornidazole-fed rats under different mating schedules (Expt 2)}

This study investigated whether a period in the cauda epididymidis was necessary for the spermatozoa to be affected by ornidazole, and whether spermatozoa that had already matured before treatment were also susceptible to the drug. Three groups of five male rats were fed for 10 days as described above, two groups with $400 \mathrm{mg}$ ornidazole $\mathrm{kg}^{-1}$ day $^{-1}$ and one with vehicle. One ornidazole-treated group was mated only once (on day 10) and the other group three times (on days 4, 7 and 10) to examine whether the frequency of mating affected the antifertility action of ornidazole. The inseminated females were killed 12 days after mating and fertility was assessed as described for Expt 1 .

\section{Statistical analyses}

Comparison between parameters of spermatozoa obtained at the same time points from ornidazole- and vehicle-fed rats in Downloaded from Bioscientifica.com at 04/26/2023 07:23:42AM 
Table 1. Body and organ masses of male rats fed ornidazole at $400 \mathrm{mg} \mathrm{kg}^{-1}$ day $^{-1}$ for 11 days compared with controls

\begin{tabular}{|c|c|c|}
\hline Parameter & Control & Ornidazole \\
\hline \multicolumn{3}{|l|}{ Body mass ( $g$ ) } \\
\hline Beginning & 442 & \pm 13 \\
\hline End & $457 \pm 8$ & \pm 14 \\
\hline Gain & $15.7 \pm 2.8$ & $2.2 \pm 6.3$ \\
\hline Testis (mg) & $3.64 \pm 0.1$ & $3.50 \pm 0.07$ \\
\hline Epididymis (mg) & $1.23 \pm 0.05$ & $1.19 \pm 0.03$ \\
\hline $\mathrm{SV}+\mathrm{CG}(\mathrm{mg})$ & $1.06 \pm 0.07$ & $1.08 \pm 0.10$ \\
\hline $\mathrm{VP}(\mathrm{mg})$ & $0.59 \pm 0.06$ & $0.60 \pm 0.06$ \\
\hline Kidney (mg) & $3.04 \pm 0.10$ & $3.47 \pm \quad 0.14$ \\
\hline Liver (mg) & $18.10 \pm 0.92$ & $17.3 \pm 0.72$ \\
\hline
\end{tabular}

Values are means $\pm \operatorname{sem}(n=6)$.

SV: seminal vesicle (less secretions); CG: coagulating glands (less secretions); VP: ventral prostate.

Expt 1 was made by Student's $t$ test. In Expt 2, in which three groups of animals were compared, the Tukey multiple range test was used after one-way analysis of variance. All percentages or ratios were transformed by taking the arcsin of the square root of the ratio before statistical analysis. Where mean + SEM are given, they were generated after transformation and have been retransformed; the SEM was calculated from the difference between the retransformed mean + SEM and retransformed mean values. Two-way analysis of variance was used to compare the migration and motility parameters of spermatozoa from treated and control animals at different times of incubation. Statistical significance was accepted if $P<0.05$.

\section{Results}

\section{Fertility of male rats}

The male rats fed ornidazole displayed sluggish behaviour immediately after feeding, but haematocrits (mean \pm SEM, $48.5 \pm 2.2, n=4$ ) were not different from those of controls $(48 \pm 1.8, n=5)$. In contrast to the controls, however, the body mass of ornidazole-fed animals did not increase during the feeding period (Table 1). There were no differences in the masses of the testes and accessory organs between the control and treated rats (Table 1 ) and their ability to mate was unaffected as judged from the numbers of spermatozoa in the female tract (see Table 2).

Fertility of male rats, expressed as the number of fetuses standardized against the number of corpora lutea of the mated female, was high in the control group throughout the experiment. Treatment with ornidazole for 4 or 7 days did not reduce fertility of rats, but mating on day 10 resulted in the same low fertility in groups with and without the two earlier matings (Table 3, Expts 1, 2).

In the study in which spermatozoa in the female tract were examined, matings by the control rats yielded $58 \%$ of eggs fertilized compared with none from the ornidazole-treated group (Table 3, Expt 1, day 10). The number of eggs ovulated in the two groups was the same (Table 2).

\section{Numbers of spermatozoa in the female tract $9 \mathrm{~h}$ after mating}

There was no significant difference in the numbers of spermatozoa in the uterus, the oviductal ampulla or the cumulus of females mated to control or ornidazole-treated rats. However, there were significantly fewer spermatozoa in the oviductal isthmus and cumulus-egg complexes in the infertile rats (Table 2). As each fertilized egg in the control group contained one spermatozoon, the number of spermatozoa that had penetrated the cumulus at the time of recovery was higher in the group that was mated with control males than in those mated with treated males. No spermatozoa from the ornidazole-fed rats were seen on the surface of the zona pellucida, in the perivitelline space or in the ooplasm.

\section{Motility of spermatozoa recovered from the female tract}

There was no difference in the percentage of motile cells obtained from the uterus, oviductal isthmus or ampulla (flushed out in medium $\mathrm{H}$ ) of females mated to fertile and infertile animals (Table 2). However, all velocities and amplitudes of head displacement of spermatozoa recovered from the isthmus of females mated to ornidazole-treated males were significantly lower than those of the control animals (Table 2).

\section{Migration of spermatozoa through viscous medium}

The migration of cauda epididymal sperm cells along capillary tubes filled with methylcelluose in medium $\mathrm{H}$ was lower when the spermatozoa were recovered from infertile, ornidazole-fed rats than from control rats (Fig. 1). This occurred at 1.5 and $4.5 \mathrm{~h}$ and for the first (vanguard) and the tenth (representative of the following cohort) spermatozoa, reflecting a lower rate of progression which was statisticaliy significant for the cohort of spermatozoa.

\section{Motility of distal cauda spermatozoa incubated in various media}

The percentage of motile cells over a $7 \mathrm{~h}$ incubation was not different between the control and ornidazole-treated animals, irrespective of the medium used (Tables 4 and 5). The kinematic parameters were unaffected except in the lactate- and pyruvate-free medium, in which there was a decline in all three types of velocities for spermatozoa from the ornidazole-fed animals (Fig. 2). A sharp decline in motility in the substrateand BSA-free medium of spermatozoa from treated rats compared with those from control rats in the same medium was observed and statistical significance was indicated for the three types of velocity (Table 4).

\section{Discussion}

In the present study, ornidazole treatment for 10 days was required for the antifertility effect of orally administered ornidazole to be expressed, regardless of whether the rats were mated earlier during treatment. This finding indicates that mature epididymal spermatozoa of different ages (spermatozoa ejaculated after serial matings must be younger than those from males not ejaculating frequently) were equally susceptible to 
Table 2. Characteristics of spermatozoa recovered from the tract of female rats mated with fertile (control) and infertile males fed for 10 days with vehicle or $400 \mathrm{mg}$ ornidazole $\mathrm{kg}^{-1}$ day ${ }^{-1}$, respectively

\begin{tabular}{|c|c|c|}
\hline \multirow{2}{*}{$\begin{array}{l}\text { Site } \\
\quad \text { parameters }\end{array}$} & \multicolumn{2}{|c|}{ Mean and SEM $(n)$} \\
\hline & Control & Ornidazole-treated \\
\hline \multicolumn{3}{|l|}{ Uterus } \\
\hline Total number of spermatozoa $\left(\times 10^{-6}\right)$ & $24.6 \pm 7.6(7)$ & $6.6 \pm 2.5(6)$ \\
\hline Motile spermatozoa (\%) & $9.9+10.3(7)$ & $31.3+14.1(6)$ \\
\hline \multicolumn{3}{|l|}{ Oviductal isthmus } \\
\hline Total number of spermatozoa $\left(\times 10^{-6}\right)$ & $817 \pm 97$ & $265 \pm 86(6)^{\mathrm{a}}$ \\
\hline Motile spermatozoa (\%) & $16.5+6.3(7)$ & $25.1+7.5(6)$ \\
\hline VSL $\left(\mu \mathrm{ms}^{-1}\right)$ & $25.5 \pm 2.2(6)$ & $18.0 \pm 2.0(6)^{a}$ \\
\hline $\operatorname{VAP}\left(\mu \mathrm{ms}^{-1}\right)$ & $42.6 \pm 3.3(6)$ & $28.4 \pm 3.7(6)^{\mathrm{a}}$ \\
\hline $\operatorname{VCL}\left(\mu \mathrm{ms}^{-1}\right)$ & $67.8 \pm 3.2(6)$ & $46.6 \pm 6.2(6)^{\mathrm{a}}$ \\
\hline $\mathrm{ALH}(\mu \mathrm{m})$ & $25.9 \pm 2.3(6)$ & $17.1 \pm 2.2(6)^{\mathrm{a}}$ \\
\hline $\operatorname{LIN}(\%)$ & $39.8+2.8(6)$ & $41.8+4.6(6)$ \\
\hline STR $(\%)$ & $72.7+2.5(6)$ & $73.9+3.3(6)$ \\
\hline WOB $(\%)$ & $62.7+3.6(6)$ & $65.4+3.3(6)$ \\
\hline \multicolumn{3}{|l|}{ Oviductal ampulla } \\
\hline Total number of spermatozoa & $14.4 \pm 3.7(7)$ & $8.0 \pm 2.1(6)$ \\
\hline Number of free spermatozoa & $6.7 \pm 2.2(7)$ & $6.7 \pm 1.7(6)$ \\
\hline Motile spermatozoa $(\%)$ & $7.2+4.8(7)$ & $5.1+7.4(6)$ \\
\hline Number of spermatozoa penetrated cumulus & $7.7 \pm 2.1(7)$ & $1.6 \pm 0.5(6)^{\mathrm{a}}$ \\
\hline Number of spermatozoa in cumulus & $2.9 \pm 1.2(7)$ & $1.6 \pm 0.5(6)$ \\
\hline Number of spermatozoa in eggs & $4.8 \pm 1.1(7)$ & $0.0(6)^{\mathrm{a}}$ \\
\hline Eggs fertilized (\%) & $58.6+12.5(7)$ & $0.0(6)^{\mathrm{a}}$ \\
\hline Total number of eggs & $8.9 \pm 0.3(7)$ & $8.2 \pm 0.4(6)$ \\
\hline
\end{tabular}

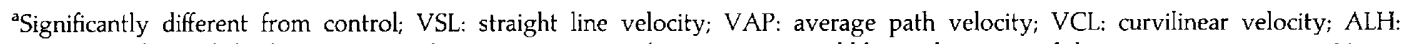
amplitude of lateral displacement; LIN: linearity; STR: straightness; WOB: wobble; explanations of these terms are given in Yeung et al. (1992).

Table 3. Effect of mating frequency on fertility of rats fed $400 \mathrm{mg}$ ornidazole $\mathrm{kg}^{-1} \mathrm{day}^{-1}$ and vehicle-fed (control) rats

Percentage fertility (number of embryos/number of corpora lutea $\times 100$ ) 12 days after pairing Days of feeding

\begin{tabular}{lcccc}
$\begin{array}{l}\text { Experiment } 1 \\
\text { Control }\end{array}$ & $87.1+11.5[43.1-98.5]$ & - & $95.9+3.3[82.4-99.9]$ & $58.6+12.5^{\mathrm{a}}[33.2-81.8](7)$ \\
Ornidazole & $96.4+2.6[86.6-100]$ & - & $88.8+10.4[45.3-97.8]$ & $0.0(6)^{\mathrm{ab}}$ \\
$\begin{array}{l}\text { Experiment 2 } \\
\text { Control }\end{array}$ & $98.3+1.5[91.3-99.8]$ & $96.1+1.8[91.3-99.1]$ & $98.7+1.1[93.5-99.9]$ & $94.4+2.6[86.9-98.9]$ \\
Ornidazole group 1 & $99.2+0.7[96-100]$ & $90.4+4.3[78.9-97.7]$ & $85.8+8.6[60.9-99.0]$ & $13.1+11.4^{\mathrm{b}}[0.6-37.6]$ \\
Ornidazole group 2 & $97.9+1.8[90.1-99.9]$ & - & - & $21.9+18.0^{\mathrm{b}}[1.0-58.8]$ \\
\hline
\end{tabular}

Values are means + SEM $[95 \%$ confidence intervals] for $n=5$ animals, unless otherwise stated.

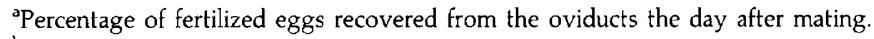

${ }^{\mathrm{b}}$ Significantly different from control $(P<0.05)$.

Ornidazole group 1: rats were mated three times (on days 4, 7 and 10); ornidazole group 2: rats were mated once (on day 10) during treatment.

the drug. The onset of infertility is later than that found in a study in which a combination of stress caused by oral gavage and drug effect was suspected to have produced the slight decline of fertility observed in the vehicle-fed group (Oberländer et al., 1994).

In studies in which numbers of spermatozoa in the female tract are examined after mating, the time after copulation and ovulation is critical. Examining soon after ejaculation provides information about the efficiency of sperm deposition and survival in the uterus before mechanisms of expulsion (leucocyte ingestion, expulsion of the vaginal plug) are activated. Examination later, but before fertilization is complete, can indicate whether the progress of the non-fertilizing spermatozoa through the female tract is hindered. However, information about the process of fertilization itself is best provided later when these events are in progress. In normal rats, spermatozoa 


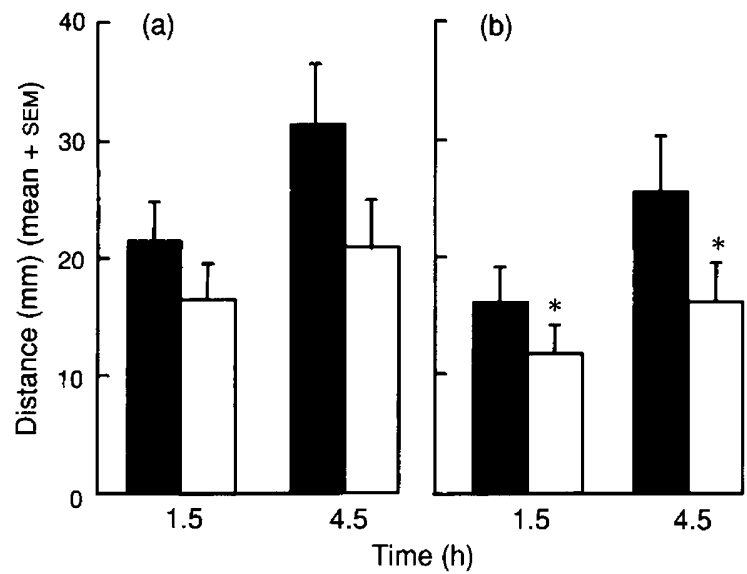

Fig. 1. The migration (mm, mean + SEM) of (a) the first spermatozoon and (b) the tenth spermatozoon along capillaries filled with $1.5 \%(\mathrm{w} / \mathrm{v})$ methylcellulose at different incubation times at $34^{\circ} \mathrm{C}$. Spermatozoa were from the distal cauda epididymidis of rats $(n=6)$ fed for 11 days

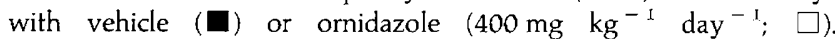
*Significantly different from controls at the same time point.

pass en masse to the uterus 2 min after ejaculation (Bedford and Yanagimachi, 1992), over 95\% of ejaculated spermatozoa are in the uterus after 15 min (Carballada and Esponda, 1992) and there is no change in the percentage motility of spermatozoa and their velocity within the uterus for at least $6 \mathrm{~h}$ (Goeden and Zenick, 1985). Migration of spermatozoa through the isthmus of the oviduct begins $20 \mathrm{~min}$ after ejaculation, and within $1 \mathrm{~h}$, one hundred or more spermatozoa are in the oviduct (Shalgi and Kraicer, 1978). In spontaneously cyclic rats, spermatozoa take between $4 \mathrm{~h}$ (Shalgi and Kraicer, 1978) and $6 \mathrm{~h}$ (Shalgi and Phillips, 1988) after mating to reach the site of fertilization in the ampulla. From then on the rate of entry of spermatozoa into the ampulla is about $3 \mathrm{~h}^{-1}$ (Shalgi and Kraicer, 1978). Fertilization occurs as soon as spermatozoa arrive and continues, such that more than $80 \%$ of ova are penetrated $8.5 \mathrm{~h}$ after mating (Shalgi and Phillips, 1988). Thus in the study reported here, the animals were paired for $60 \mathrm{~min}$ from $00.30 \mathrm{~h}$ to provide an 'interval' in which mating would occur (presumably at $01.00 \mathrm{~h}$ ); they were then killed $8.5 \mathrm{~h}$ after separation $(10.00 \mathrm{~h})$ so that most eggs from females mated with control males would be fertilized. Although this regimen provides data from all compartments of the female tract, it inevitably allows time for spermatozoa to be lost from the tract, particularly from the uterus.

Since the number of ejaculated spermatozoa reported for rats (about $60 \times 10^{6}$ immediately recovered from the uterus (Blandau, 1973; Carballada and Esponda, 1992) or 25$160 \times 10^{6}$ estimated from the loss of spermatozoa from the cauda epididymidis (Ratnasooriya and Wadsworth, 1987; Yeung and Cooper, 1994)) was higher than those recovered from the control animals in the study reported here, $9 \mathrm{~h}$ after mating, disposal of uterine spermatozoa must have started. This is reflected in the large standard error of the means and the absence of vaginal plugs from most rats during examination. Whether the lower than control (but statistically nonsignificant) numbers of spermatozoa in the uterus of ornidazole-treated male rats implies that the ejaculatory process was not normal or represents a greater loss of spermatozoa from the vagina through increased ingestion by leucocytes or enhanced expulsion of the vaginal plug cannot be determined from the study. However, the viability of spermatozoa, as judged from their motility, was not impaired. Nevertheless, lower numbers of spermatozoa are unlikely to explain the significantly reduced number of spermatozoa in the oviductal isthmus at recovery, since normally $<0.01 \%$ of spermatozoa from the uterus enter the oviduct (see Hunter, 1975). Despite the consistently lower velocities of spermatozoa recovered from this site, neither the number nor the percentage motility of spermatozoa found in the oviductal ampulla was reduced in the infertile animals, and therefore the number of motile spermatozoa in the tract cannot account for the reduced fertility. Spermatozoa from the infertile males were present within the cumulus mass, but were never observed in the eggs and this finding is consistent with the infertility previously demonstrated. The conclusion that transport to the site of fertilization is not the cause of infertility suggests that other aspects of the ejaculated spermatozoa are responsible for their failure to fertilize eggs.

Since the fertility of female rats is unaffected by the same dose of ornidazole for 64 days (McClain and Downing, 1988b), the reductions in number and velocity of spermatozoa recovered from the oviductal isthmus in the present study are unlikely to be mediated by the drug passing to the female from the ejaculate. The lower velocities of spermatozoa may reflect a decline in vigour that prevents them from penetrating the cumulus or the zona pellucida, and the ability of spermatozoa from the treated animals to negotiate a viscous medium in vitro when provided with glucose and lactate and pyruvate was significantly decreased.

As the medium used to flush the spermatozoa from the female tract and to prepare the viscous medium contained glucose, lactate and pyruvate, further studies were performed to determine the ability of spermatozoa to survive in other media, including one containing $25 \mathrm{mmol}$ potassium $\mathrm{l}^{-1}$ to mimic high potassium concentrations of female tract fluids that enhance capacitation (Toyoda and Chang, 1974). Over the periods studied (up to $7 \mathrm{~h}$ ), no differences in kinematic parameters were found between spermatozoa from ornidazole- and control-fed rats in any medium tested, with the exception of a decline in velocities of spermatozoa incubated in the medium that contained glucose but not lactate or pyruvate; in the presence of lactate, velocities were maintained at the control values. This finding indicates a specific effect on glucose metabolism (after II days of treatment) before a more general effect on energy production revealed in the previous study in which kinematics of distal epididymal spermatozoa were reduced in medium containing all three substrates when rats were infertile after 15 days of treatment (Oberländer et al. 1994). Nevertheless, survival of spermatozoa in such test media was maintained as revealed by the unchanged percentage of motile cells. Lower percentages of motility were found after incubation in albumin- and substrate-free medium than in controls and this also suggests defects in the use of endogenous lipid substrates. Further studies on the enzyme activities of these spermatozoa would elucidate which pathways are involved.

Spermatozoa from 6-chloro-6-deoxyglucose-treated rats display a similar time-dependent reduction in percentage motility 
Table 4. Percentage motility and velocities of spermatozoa from male rat distal cauda epididymidis incubated in different media for up to $7 \mathrm{~h}$

\begin{tabular}{|c|c|c|c|c|c|c|c|c|}
\hline \multirow[b]{2}{*}{ Time (h) } & \multicolumn{2}{|c|}{$\begin{array}{l}\text { Motile cells } \\
(\%)\end{array}$} & \multicolumn{2}{|c|}{$\begin{array}{l}\text { Averge velocity } \\
\left(\text { VAP, } \mu \mathrm{m} \mathrm{s}^{-1}\right)\end{array}$} & \multicolumn{2}{|c|}{$\begin{array}{l}\text { Curvilinear velocity } \\
\left(V C L, \mu \mathrm{m} \mathrm{s}^{-1}\right)\end{array}$} & \multicolumn{2}{|c|}{$\begin{array}{l}\text { Straightline velocity } \\
\left.\text { (VSL, } \mu \mathrm{m} \mathrm{s}^{-1}\right)\end{array}$} \\
\hline & Control & Ornidazole & Control & Ornidazole & Control & Ornidazole & Control & Ornidazole \\
\hline \multicolumn{9}{|c|}{ Medium $\mathrm{H}$} \\
\hline 0 & $78.0+4.5(6)$ & $61.6+5(6)$ & $60.2 \pm 5.4(6)$ & $57.5 \pm 3.2(6)$ & $73.1 \pm 4.0(6)$ & $68.5 \pm 3.0(6)$ & $56.9 \pm 5.5(6)$ & $53.6 \pm 3.4(6)$ \\
\hline 3 & $66.9+5.1(6)$ & $58.8+7.3(6)$ & $65.6 \pm 3.4(6)$ & $61.7 \pm 5.8(6)$ & $81.8 \pm 3.9(6)$ & $76.9 \pm 6.0(6)$ & $56.9 \pm 4.8(6)$ & $54.6 \pm 5.1(6)$ \\
\hline 0 & $73.6+4.3(5)$ & $76.2+7.8(5)$ & $60.8 \pm 6$ & $50.8 \pm 2.2(5)$ & $74.1 \pm 4.7(5)$ & $67.4 \pm 1.8(5)$ & $54.6 \pm 6.5(5)$ & $43.4 \pm 3.3(5)$ \\
\hline 3 & $61.3+8.2(5)$ & $62.0+8.8(5)$ & $70.1 \pm 3.2(5)$ & $66.0 \pm 5.2(5)$ & $86.4 \pm 3.8(5)$ & $83.8 \pm 8.1(5)$ & $59.1 \pm 6.1(5)$ & $55.7 \pm 4.1(5)$ \\
\hline 7 & $46.7+9.9(5)$ & $54.9+9.8(5)$ & $60.2 \pm 5$ & $64.1 \pm 6.5(5)$ & $74.5 \pm 5.5(5)$ & $80.7 \pm 6.8(5)$ & $53.8 \pm 4.6(5)$ & $55.6 \pm 6.3(5)$ \\
\hline \multicolumn{9}{|c|}{ Glucose-free } \\
\hline 3 & $67.8+9.2(6)$ & $73.6+7.2(6)$ & $71.5 \pm 5.4(5)$ & $63.9 \pm 4 \quad(6)$ & $100.5 \pm 4.7(5)$ & $88.9 \pm 6.3(6)$ & $50.6 \pm 4.9(5)$ & $50.7 \pm 2.1(6)$ \\
\hline 7 & $46.2+13$ & $13.9+13.8(6)$ & $50.4 \pm 11$ & $17.6 \pm 11.2(4)^{\mathrm{a}}$ & $71.7 \pm 14.8(6)$ & $29.1 \pm 18.1(4)^{a}$ & $40.2 \pm 8.7(6)$ & $11.8 \pm 8.4(4)^{\mathrm{a}}$ \\
\hline
\end{tabular}

Values are means + SEM (for transformed data) or means \pm SEM $(n)$; ornidazole fed at $400 \mathrm{mg} \mathrm{kg}^{-1}$ day ${ }^{-1}$ for 11 days.

${ }^{a}$ Significantly different from controls.

Table 5. Amplitude of lateral displacement $(\mathrm{ALH})$ and derived kinematic parameters of spermatozoa from male rat distal cauda epididymidis incubated in different media for up to $7 \mathrm{~h}$

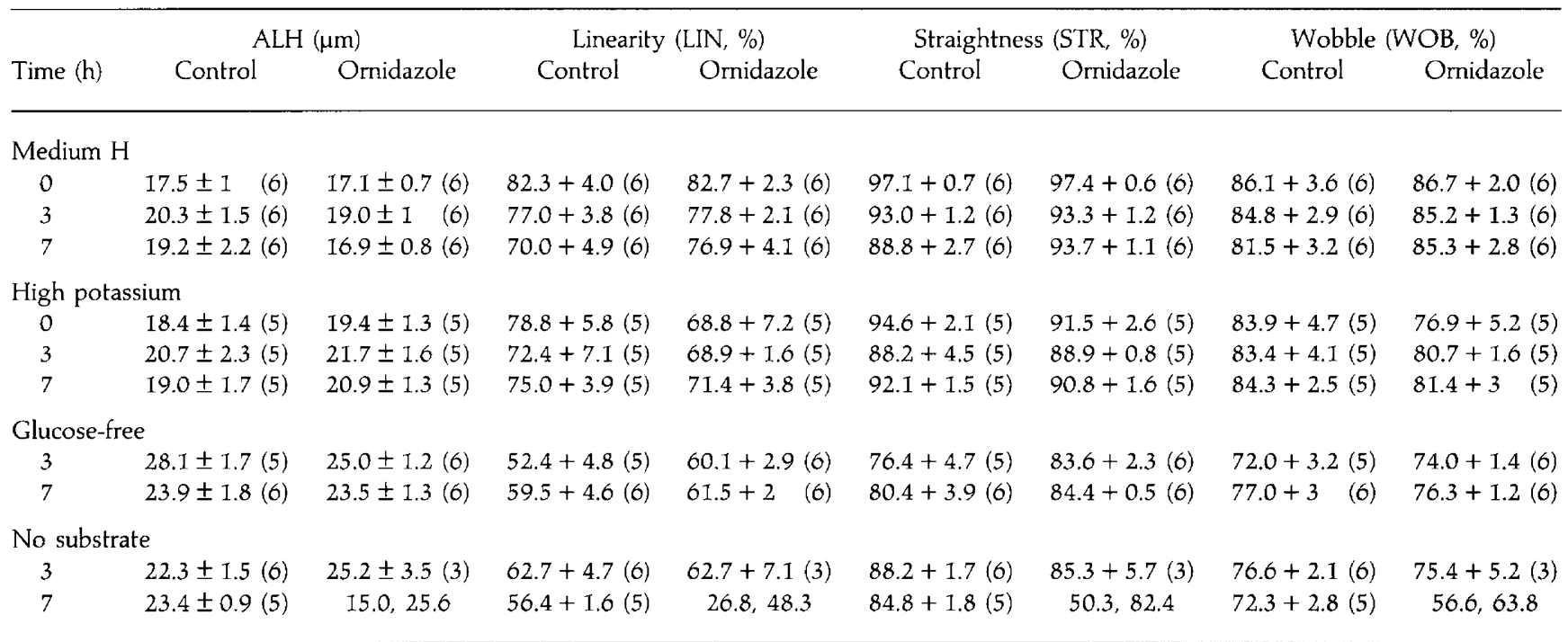

Values are means + SEM (for transformed data) or means \pm SEM ( $n$ ); ornidazole was fed at $400 \mathrm{mg} \mathrm{kg}^{-1} \mathrm{day}^{-1}$ for 11 days.

in lactate-free medium, which reflects their well-established metabolic lesion of glycolysis (Ford, 1982). When incubated in vitro with $\alpha$-chlorohydrin, glycolysis of ovine and porcine spermatozoa is inhibited and ATP dissipation occurs when glycolysable sugars are also present (Ford et al., 1977; Ford and Harrison, 1985, 1986). There is no evidence to show that the effect of ornidazole in vivo is mediated by $\alpha$-chlorohydrin.

In an earlier report on the antifertility action of ornidazole (Oberländer et al., 1994), we discounted the possibility that the antifertility effect was caused by any contaminating epichloro- hydrin used in its synthesis (Hoffer and Grunberg, 1974; see also Fig. 3), on the basis of the antifertility efficacy of epichlorohydrin. The evidence that the motility of spermatozoa from ornidazole-treated rats cannot be sustained in medium free from lactate and pyruvate, is consistent with results obtained from infertile, 6-chloro-6-deoxyglucose-fed rats (Ford and Waites, 1980). The knowledge that 6-chloro-6deoxyglucose can be converted into $\alpha$-chlorohydrin in rats (Jones and Dobbie, 1991) and that both compounds interfere with glycolysis (Ford et al., 1977; Ford, 1982) raises the Downloaded from Bioscientifica.com at 04/26/2023 07:23:42AM 


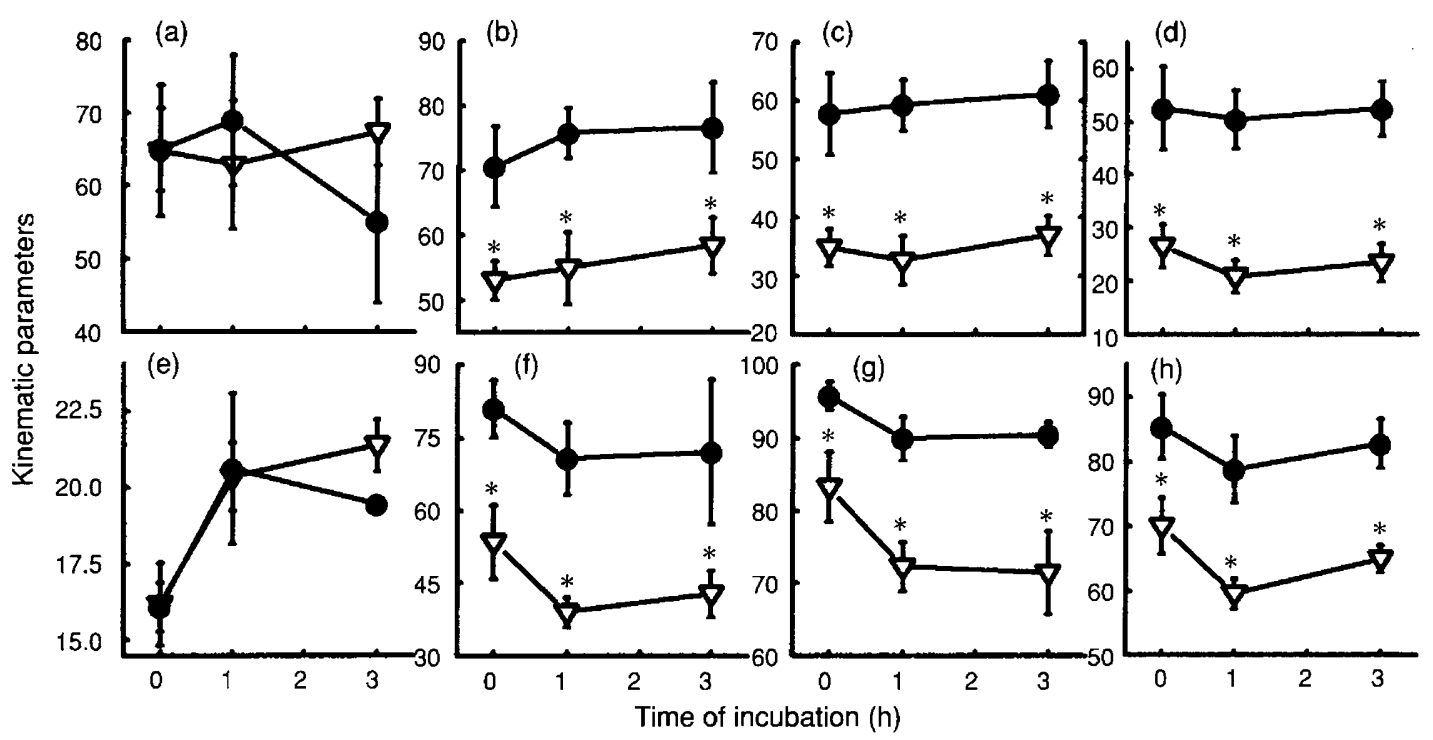

Fig. 2. Kinematic parameters of spermatozoa from the distal cauda epididymidis of rats fed for 11 days with vehicle (O) or ornidazole $(\nabla)$ when incubated in medium $\mathrm{H}$ lacking lactate and pyruvate at different times of incubation (abscissa). (a) Motility (\%); (b) curvilinear velocity $\left(\mu \mathrm{m} \mathrm{s}^{-1}\right.$ ); (c) average path velocity $\left(\mu \mathrm{m} \mathrm{s}^{-1}\right)$; (d) straight line velocity $\left(\mu \mathrm{m} \mathrm{s}^{-1}\right)$; (e) amplitude of lateral displacements $(\mu \mathrm{m})$; (f) linearity $(\%) ;(\mathrm{g})$ straightness $(\%)$; $(\mathrm{h})$ wobble $(\%)$. Values are means \pm SEM of six rats. ${ }^{*}$ Significantly different from controls at same timepoint.<smiles>Cc1ncc([N+](=O)[O-])n1C(O)C(O)CCl</smiles>

ORNIDAZOLE<smiles>OC(O)C(O)CCl</smiles>

\section{ALPHA-CHLOROHYDRIN}

Fig. 3. Chemical structures of ornidazole (2(chloromethyl)2-methyl 5 -nitroimidazole 1-ethanol), $\alpha$-chlorohydrin and epichlorohydrin.

possibility that $\alpha$-chlorohydrin, as a contaminant, produced from contaminating epichlorohydrin, or liberated from ornidazole in the animal, is responsible for the antifertility action of the administered nitroimidazole. As a sole contaminant, based on a $1 \%$ impurity claimed by the manufacturer, racemic $\alpha$-chlorohydrin would be present at $4 \mathrm{mg} \mathrm{kg}^{-1}$ day ${ }^{-1}$, or $2 \mathrm{mg} \mathrm{kg}^{-1}$ day ${ }^{-1}$ of the effective (S)-enantiomer. To achieve the present result of no fertilization after treatment for 10 days, $>10 \mathrm{mg} \mathrm{kg}^{-1}$ day $^{-1}$ of the racemic mixture is required (Vickery et al., 1974) and three of seven animals still had fertilized eggs 14 days after administration of (S)- $\alpha$ chlorohydrin at $3.25 \mathrm{mg} \mathrm{kg}^{-1}$ day $^{-1}$ (Ford et al., 1977). Thus, it is unlikely that contaminating $\alpha$-chlorohydrin is solely responsible for the antifertility action. However, there is evidence that $\alpha$-chlorohydrin is generated from ornidazole in rats, since a major urinary metabolite is 2-methyl-5nitroimidazole, which lacks the chloropropanol side-chain of ornidazole, although the nature of the side-chain released was not elucidated (Schwartz et al., 1979).

In conclusion, ornidazole renders male rats infertile without affecting transport of spermatozoa in the female tract, but probably via effects on energy metabolism and possibly other sperm functions required for capacitation.

This work was financed by the Deutsche Forschungsgemeinschaft, DFG Research Group 'Regulation of male reproductive function', $\mathrm{Ni}$ $130-11 / C$. The authors thank E. Nieschlag for his suggestions and encouragement and E. Möllmann for help with monitoring the animals. This work is part of a doctoral thesis by $\mathrm{G}$. Oberländer and we gratefully acknowledge the support of $G$. Clemen, Institute of Special Zoology and Comparative Embryology of the University, Münster.

\section{References}

Bedford JM and Yanagimachi R (1992) Initiation of sperm motility after mating in the rat and hamster Journal of Andrology 13 444-449

Blandau RJ (1973) Sperm transport through the mammalian cervix: comparative aspects. In The Biology of the Cervix pp 285-304 Eds RJ Blandau and K Moghissi. University of Chicago Press, Chicago

Carballada R and Esponda P (1992) Role of fluids from seminal vesicles and coagulating glands in sperm transport into the uterus and fertility of rats Journal of Reproduction and Fertility $95639 \cdots 648$

Ford WCL (1982) The mode of action of 6-chloro-6-deoxy sugars as antifertility agents in the male. In Progress Towards a Male Contraceptive pp 159-184 Eds SL Jeffcoate and M Sandler. John Wiley \& Sons, Chichester

Ford WCL and Harrison A (1985) The presence of glucose increases the lethal effect of $\alpha$-chlorohydrin on ram and boar spermatozoa in vitro Journal of Reproduction and Fertility 73 197-206

Ford WCL and Harrison A (1986) The concerted effect of $\alpha$-chlorohydrin and glucose on the ATP concentration in spermatozoa is associated with the accumulation of glycolytic intermediates Journal of Reproduction and Fertility $77537-545$ 
Ford WCL and Waites GMH (1980) The control of male fertility by 6-chloro6-deoxysugars Reproduction, Nutrition and Development 20 1101-1109

Ford WCL, Harrison A and Waites GMH (1977) Effects of the optical isomers of $\alpha$-chlorohydrin on glycolysis of ram testicular spermatozoa and the fertility of male rats Joumal of Reproduction and Fertility 51 105-109

Goeden H and Zenick H (1985) Influence of the uterine environment on rat sperm motility and swimming speed Journal of Experimental Zoology 333 247-25I

Hoffer M and Grunberg E (1974) Synthesis and antiprotozoal activity of I-(3-chloro-2-hydroxypropyl)-substituted nitroimidazoles Journal of Medical Chemistry 17 1019-1020

Hunter RHF (1975) Transport, migration and survival of spermatozoa in the female genital tract: species with intra-uterine deposition of semen. In The Biology of Spermatozoa pp 145-155 Eds ESE Hafez and CG Thibault. Karger, Basel

Jones AR and Dobbie MS (1991) The male antifertility activity of 6-chloro-6deoxyglucose Contraception 44 649-655

McClain RM and Downing JC (1988a) The effect of ornidazole on fertility and epididymal sperm function in rats Toxicology and Applied Pharmacology 92 488-496

McClain RM and Downing JC (1988b) Reproduction studies in rats treated with ornidazole Toxicology and Applied Pharmacology 92 480-487

Oberländer G, Yeung CH and Cooper TG (1994) Induction of reversible infertility in male rats by oral ornidazole and its effects on sperm motility and epididymal secretions Journal of Reproduction and Fertility 100 551-559

Patanelli DJ (1975) Suppression of fertility in the male. In Handbook of Physiology, Vol. 5 Endocrinology. Section 7 Male Reproductive System pp 245-258 Eds RO Greep and DW Hamilton. American Physiological Society, Washington DC

Ratnasooriya WD and Wadsworth RM (1987) Effect of mating on sperm distribution in the reproductive tract of the male rat Gamete Research 17 261-266

Shalgi R and Kraicer PF (1978) Timing of sperm transport, sperm penetration and cleavage in the rat Journal of Experimental Zoology 204 353-360

Shalgi R and Phillips DM (1988) Motility of rat spermatozoa at the site of fertilization Biology of Reproduction 39 1207-1213

Schwartz DE, Jordan J-C, Vetter W and Oesterhelt G (1979) Metabolic studies of ornidazole in the rat, in the dog and in man Xenobiotica 9 571 581

Toyoda Y and Chang MC (1974) Capacitation of epididymal spermatozoa in a medium with $\mathrm{K} / \mathrm{Na}$ ratio and cyclic AMP for the fertilization of rat eggs in vitro Journal of Reproduction and Fertility 36 125-134

Turner TT and Cesarini DM (1983) The ability of the rat epididymis to concentrate spermatozoa: responsiveness to aldosterone Journal of Andrology 4 197-202

Vickery BH, Erickson GI and Bennett JP (1974) Mechanisms of antifertility action of low doses of a-chlorohydrin in the male rat Journal of Reproduction and Fertility 38 1-10

Yeung $\mathrm{CH}$ and Cooper TG (1994) Study of the role of epididymal $\alpha$-glucosidase in the fertility of male rats by the administration of the enzyme inhibitor castanospermine Journal of Reproduction and Fertility 102 401-410

Yeung CH, Oberländer G and Cooper TG (1992) Characterization of the motility of rat spermatozoa by computer-aided objective measurement Journal of Reproduction and Fertility 96 427-441 